\title{
Research on Dynamic Relationship between Exchange Rate and Stock Price-Based on GARCH-in-Mean Model
}

\author{
Weihan Zhang, Peijuan Yang \\ Department of Finance, College of Economics, Jinan University, Guangzhou, China \\ Email: zsn890@163.com
}

How to cite this paper: Zhang, W.H. and Yang, P.J. (2018) Research on Dynamic Relationship between Exchange Rate and Stock Price-Based on GARCH-in-Mean Model. Journal of Service Science and Management, 11, 691-702.

https://doi.org/10.4236/jssm.2018.116046

Received: November 26, 2018

Accepted: December 25, 2018

Published: December 28, 2018

Copyright $\odot 2018$ by authors and Scientific Research Publishing Inc. This work is licensed under the Creative Commons Attribution International License (CC BY 4.0).

http://creativecommons.org/licenses/by/4.0/

\begin{abstract}
The reform of the exchange rate system has brought epoch-making changes to China's capital market. Based on the monthly exchange rate of the US dollar against RMB exchange rate and the Shanghai Composite Index (SHCI) from June 2005 to August 2017, this paper empirically tests the dynamic relationship between China's exchange rate and stock price using the GARCHin-Mean model. The empirical results show that China's stock market doesn't have a high level of openness to foreign investment; there is a two-way influence mechanism between China's stock price and exchange rate market, and the appreciation of RMB will bring the stock market down; from the perspective of market fluctuations, the uncertainty of the exchange rate will not have an effect on the trend of the stock market, and the risk transmission mechanism between the two markets is not significant.
\end{abstract}

\section{Keywords}

Exchange Rate, Stock Price, GARCH-in-Mean Model

\section{Introduction}

On August $11^{\text {th }}, 2015$, the People's Bank of China announced the launch of a new round of exchange rate reform to adjust the quotation mechanism of RMB against the US dollar exchange rate. Since then, this round of exchange has been changed for three years. Since the beginning of last year, the trend of RMB has reversed. On September 1, RMB central parity, onshore and offshore RMB collectively rose to a new high of the last 14 months. In August, the onshore RMB embraced the biggest monthly increase since the exchange rate reform in 2005. 
On the same day, the A-share market also showed a rising picture. The relationship between stock prices and exchange rates has always been a topic worthy of our study. The change of exchange rate not only affects the macroeconomic operation of a country, but also affects the business behavior and performance of the microeconomic entity, which as a result, causes fluctuations in the company's stock price and yield [1]. With the development of global financial liberalization, the domestic market has continuously deepened its links with global financial markets through the "Shanghai-Hong Kong Stock Connect" and "bond-to-bond" approaches. China's financial system is still in the stage of development and improvement, and financial stability plays an important role in economic stability and sustainable economic development. With the degree of liberalization of the domestic capital market and the deepening of the degree of opening up to the outside world, the degree of China's integration into economic globalization has continuously increased, and the foreign exchange market will serve as a bridge linking domestic and foreign capital markets. In order to prevent external shocks from causing domestic financial market turmoil through the foreign exchange market, it is necessary to clarify the dynamic transmission relationship between exchange rate and domestic financial asset prices, and then study and design corresponding response mechanisms. Therefore, an in-depth study of the interaction between the stock market and the foreign exchange market will not only help to deeply understand the correlation between financial markets, but also have important reference significance for policy development in the prevention of financial risks and financial market reform.

In the study of the relationship between exchange rate and stock price, the Goods Market Approaches (Dornbusch and Fischer, 1980) and the Portfolio Balance Approaches (Gavin, 1989) have earlier discussed the relationship between exchange rate and stock price from the perspective of theoretical model. In empirical research, there are many studies in developed countries and emerging economies, but no consistent conclusions have been reached. For the study of the relationship between the RMB exchange rate and China's stock price, most scholars believe that there is a long-term causal relationship between exchange rate and stock price. Liu Lin, Meng Yu and Yang Kun (2015), Deng Yu and Yang Chaojun (2007) found that there is a long-term stable cointegration relationship between the stock price and the exchange rate, while Zhao Jinwen and Zhang Jingsi (2013) found that there was a short-term linkage between the stock price and the exchange rate [2] [3]. The conclusions are diverse and they pay less attention to the risk transmission between the two, which is the most important factor I want to discuss in this paper.

The rest of the paper is structured as follows: the second part is the literature review and possible innovations in this paper; the third part is the design of the model; the fourth part is the data selection and its descriptive statistical analysis; the fifth part is the empirical result analysis; The final section shows the main conclusions and policy recommendations. 


\section{Literature and Theory}

There are two classic theoretical assumptions about the relationship between exchange rates and stock prices in the academic field: Goods Market Approaches and Portfolio Balance Approaches.

The Goods Market Approaches (Dornbusch and Fischer, 1980) starts from the perspective of current account or trade balance, and believes that exchange rate fluctuations have an impact on the stock market [4]. The extent of its impact depends on the importance of international trade in the overall economy of the country and the imbalance of trade. As the main factor of foreign trade, exchange rate changes directly affect the competitiveness of domestic products in the international market, thus affecting the changes in import and export volume. The increase or decrease of import and export volume will inevitably affect the production and operation of the enterprises related to import and export, and thus the changes in stock prices caused by the impact of business performance. In addition, exchange rate changes will not only affect the transaction costs and exposures of foreign currency denominated companies, but may also trigger domestic inflation through changes in the price of imported goods, causing stock market price fluctuations.

The Portfolio Balance Approaches (Gavin, 1989) mainly explains the interaction between the exchange rate and stock price based on the capital account, and believes that stock price changes will lead to exchange rate fluctuations, and there is a negative correlation between the two. The exchange rate is the same as ordinary commodities, and its price depends on the supply and demand of the currency in the foreign exchange market. When the domestic stock market is in a bull market, the wealth effect expands, thereby stimulating local currency demand and interest rates. According to the interest rate parity theory, the international capital inflow is triggered, resulting in the appreciation of the local currency. The decline in stock prices will shrink the wealth of investors, and the "Squeezing Effect" will also weaken the influence of the wealth effect, thereby reducing investment and demand for the domestic currency, causing a fall of interest rates, and lower interest rates cause capital outflows, which in turn leads to the depreciation of the domestic currency.

The above theoretical hypothesis clearly clarify the theoretical relationship between the exchange rate and the stock price, but based on the diversification of the actual situation, the empirical results between the two are inconsistent. Domestic scholars have also conducted relevant empirical research on the relationship between the foreign exchange market and the domestic stock market. The main conclusions are different when it comes to the short-term and long-term relationship between the exchange rate and the stock price, and also there is an inconsistency on whether the relationship between the two is positive or negative. Most scholars believe that there is a long-term causal relationship between exchange rate and stock price. Liu Lin, Meng Yu and Yang Kun (2015) used the threshold cointegration test and the TVP-VAR model with stochastic 
volatility to study the relationship between the two. The conclusion shows that in the long run, there is a negative relationship between the exchange rate and the stock price. And there is a time-varying feature between the two, which means the depreciation of RMB against US dollar may lead to an increase in the stock price, but vice is not necessarily. The relationship between the exchange rate and the stock price depends mainly on the overall macroeconomic environment. The results of Deng Yu and Yang Chaojun (2007) found that there is a long-term stable cointegration relationship between the stock price and the exchange rate, and there is a one-way Granger causality from the exchange rate to the stock price which is that the appreciation of $\mathrm{RMB}$ is accompanied by a rise in the stock price. Zhao Jinwen and Zhang Jingsi (2013) found that the appreciation of RMB will lead to short-term international capital profit outflows, so that the currency supply scissors will widen, and the stock price will fall, causing the continual flow-out of the short-term capital. Thus, RMB will depreciate in turn, and short-term capital will recycle, and the money supply scissors will shrink and the stock price will rise to a reasonable level. The conclusion that the relationship between RMB exchange rate and the stock price is positive comes out. In addition, Ba Shusong and Yan Min (2009) believe that the monetary market serves as a bridge between the stock market and the foreign exchange market. When studying the relationship between stock prices and exchange rates, we won't see the whole picture if we neglect the monetary market. The relationship will be distorted. So treating stock price and exchange rate as endogenous variables, and the spread as an exogenous one, based on the vector autoregressive multivariate EGARCH model, the exchange rate has a positive guiding relationship in the short term, meaning RMB depreciation guides the stock price to rise; and in the long run, the exchange rate has a negative guiding relationship with the stock price. Some scholars believe that the long-term relationship between the two is not significant. Li Yaqiong and Huang Lihong (2010) proposed that there is no long-term equilibrium relationship between the stock return rate and $\mathrm{RMB}$ exchange rate, but it cannot refuse the short-term one-way Granger causality, that is, RMB nominal exchange rate is the Granger reason for the stock return rate. However, Bu Lin, Li Zheng and Zhang Xinyue (2015) have studied that there is not even a causal relationship between the stock price and the exchange rate.

The discussions of the literature above focus on the causal relationship between exchange rate and stock price, and they pay less attention to the risk transmission between the two. Therefore, the possible contribution of this paper is to use the GARCH-in-Mean model to apply the research ideas of co-movement to the study of exchange rate and stock price, not only paying attention to interaction effect of the mean value of the two, but also to the risk conduction between the stock market and the foreign exchange market.

\section{Modeling}

This paper focuses on the following three issues when designing the model. First, 
considering the endogeneity between exchange rate changes and stock prices, this paper constructs a VAR model containing exchange rate changes and stock prices as the basic framework of our empirical analysis. Admittedly, there are many factors that affect stock market movements. A complete VAR system is obviously not limited to two variables. However, as Frankel \& Romer (1999) suggests, a bivariate reduced-form is the most intuitive stable structure when our focus is the correlation of the two variables [5] [6] [7] [8].

Second, the exchange rate will affect stock prices in two ways. One is the changes of exchange rate, and the other is the expectation of exchange rate uncertainty. Most of the existing studies directly measure uncertainty with "variation", but in fact, the root of uncertainty lies in "fluctuation" rather than simple change. Therefore, the exchange rate volatility (i.e., standard deviation) is obviously more accurate and intuitive to measure uncertainty. In view of this, this paper introduces the ratio of exchange rate changes (mean) and volatility (standard deviation) as explanatory variables to the VAR model, in order to differentiate the analysis of stock prices changes caused by exchange rate changes and exchange rate uncertainty expectations respectively [9].

Finally, using the ideas of Engle et al. (1987) and Engle \& Kroner (1995) for reference, this paper reconstructs the variance structure of each variable by using the generalized autoregressive conditional heteroskedasticity (GARCH) model, and generates the volatility as an explanatory variable based on this. Consequently, we have the following GARCH-in-Mean model [9]:

Mean Equation:

$$
y_{t}=\mu+\sum_{i=1}^{q} \Gamma_{i} y_{t-i}+\Psi \sqrt{h_{t}}+\varepsilon_{t}
$$

Different from the traditional VAR model, the GARCH-in-Mean model fully considers the heteroscedasticity of the explanatory variable with time, and generates the variance-covariance matrix based on the GARCH process described in Equation (2).

Variance Equation:

$$
H_{t}=C^{\prime} C+A^{\prime} \varepsilon_{t-1} \varepsilon_{t-1}^{\prime} A+B^{\prime} H_{t-1} B+D^{\prime} \xi_{t-1} \xi_{t-1}^{\prime} D
$$

Among them, the explained variable $y_{t}$ is the exchange rate representative variable and the stock market performance in period $t, y_{t}=\left[\begin{array}{c}\text { exchange rate } \\ \text { stock price }\end{array}\right]$. $y_{t-i}$ as an explanatory variable represents the lag term of each order from 1 to $i$ of $y_{t} \cdot \sqrt{h_{t}}$ is the standard deviation vector of conditional heteroskedasticity which is derived from the square of the diagonal element of the covariance matrix $H_{t}=\left[\begin{array}{ll}h_{11, t} & h_{21, t} \\ h_{12, t} & h_{22, t}\end{array}\right]$ respectively. $\quad \mu=\left[\begin{array}{l}\mu_{e, t} \\ \mu_{s, t}\end{array}\right]$ is the constant vector. $\Gamma_{j}=\left[\begin{array}{ll}\gamma_{11}^{(j)} & \gamma_{21}^{(j)} \\ \gamma_{12}^{(j)} & \gamma_{22}^{(j)}\end{array}\right], j=1, \cdots, p$, is the autoregressive coefficient matrix, characterizing the influence coefficient of the $f^{\text {th }}$ order lag of the $y_{t}$ vector. $\varepsilon_{t}=\left[\begin{array}{l}\varepsilon_{e, t} \\ \varepsilon_{s, t}\end{array}\right]$ 
is the interference term of $y$ in $t$ period, a normal distribution obeying a mean of zero and a covariance matrix of $H_{t} . \quad \Psi=\left[\begin{array}{ll}\Psi_{11} & \Psi_{21} \\ \Psi_{12} & \Psi_{22}\end{array}\right]$, the coefficient matrix of $\sqrt{h_{t}}$, measures the effect of volatility on the conditional mean.

Our focus on the mean equation is the lag effect of the exchange rate and the stock price itself, that is, the significance and symbol of the autoregressive coefficient matrix $\Gamma_{j}$ are investigated. The statistical significance of the hysteresis effect is investigated by the joint significance test of the coefficient. And the signs of the long-term influence ${ }^{1}$ judge the direction of influence.

In the variance equation, the explained variable $H_{t}$ represents the covariance matrix; $C=\left[\begin{array}{cc}c_{11} & c_{12} \\ 0 & c_{22}\end{array}\right], \quad B=\left[\begin{array}{ll}b_{11} & b_{12} \\ b_{21} & b_{22}\end{array}\right], \quad A=\left[\begin{array}{ll}a_{11} & a_{12} \\ a_{21} & a_{22}\end{array}\right]$ represent the constant matrix, the covariance autoregressive (AR) coefficient matrix, and the covariance moving average (MA) coefficient matrix, respectively. Among them, the upper diagonalization of the constant matrix $C$ guarantees the semi-definiteness of the covariance matrix $H_{t}$, while the AR coefficient matrix and the MA coefficient matrix can be used to investigate the short-term and long-term lag effects of the volatility, respectively.

\section{Samples and Data}

\subsection{Sample Interval and Data Selection}

This paper selects the monthly data from June 2005 to August 2017 as a sample, covering all sample data from the implementation of the managed floating exchange rate system based on market supply and demand and adjusted with reference to a basket of currencies. After the logarithmic difference, a sample of 146 monthly yields is available. The closing price of the last trading day of each month in China's stock market performance index (000001.SH) is used as the monthly benchmark; the exchange rate is the nominal exchange rate of RMB to US dollar using the direct price method on the last day of each month (USDCNY) .EX) [5] [6] [7] [8] [9]. All the data are from Wind databases.

\subsection{Data Processing and Descriptive Statistical Analysis}

The trend of China's stock market and exchange rate market is shown in Figure 1. The two dotted lines represent two key time points for China's implementation of exchange rate regime reform. On July 21, 2005, China adjusted the US dollar/RMB official exchange rate from 8.27 to 8.11 , and announced the abolition of the monetary policy pegged to US dollar only. Since then, China's exchange rate reform has officially begun. Prior to this, China's RMB exchange

${ }^{1}$ Referring to the method of Grier \& Smallwood (2007), the long-term effects of policy changes on spillover effects are examined by constructing the "long-term equilibrium effect" indicator $\gamma_{e s}^{L R}$ of the macroeconomic policy variation coefficient. Correspondingly, this paper also constructs the "long-term equilibrium effect" indicator $\Psi_{e s}^{L R}$ of the policy change volatility coefficient to distinguish the long-term effects of policy uncertainty expectations on spillover effects. 


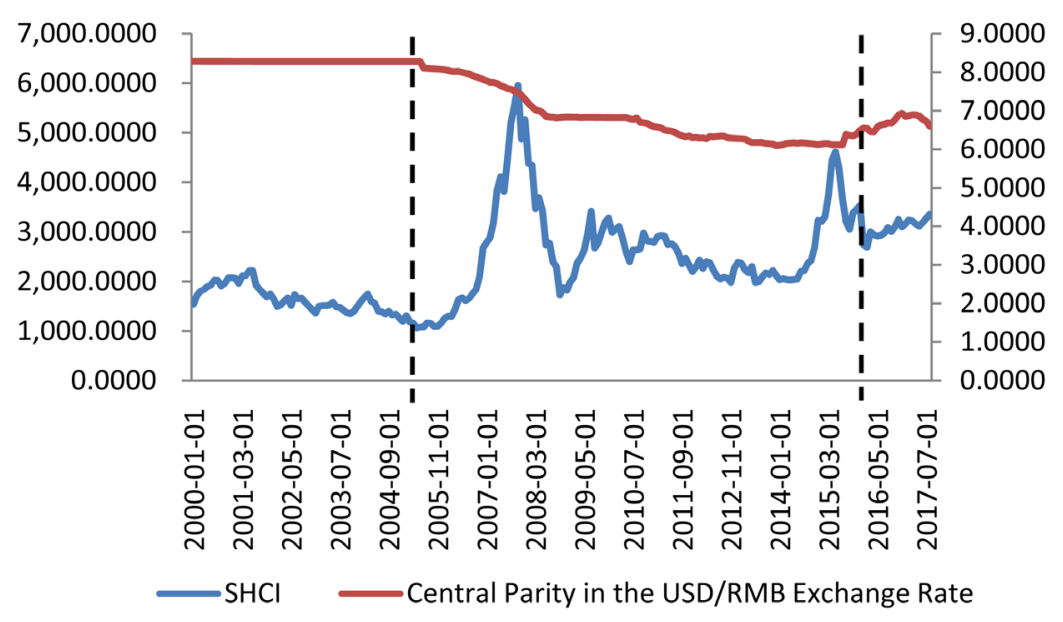

Figure 1. Overview of the trend of China's stock market and exchange rate market.

rate has been informally linked to the US dollar. Since the fixed exchange rate system implemented in 1994, and the sustained growth of China's economic growth in recent years, a large number of RMB appreciation expectations have been accumulated, so RMB has continued to appreciate for 10 years. In June 2010, China restarted the reform of RMB exchange rate formation mechanism to reinvigorate the exchange rate market, and the stock market was gradually undergoing repair and adjustment.

On August 11, 2015, the People's Bank of China announced the adjustment of the central parity rate mechanism for RMB against the US dollar. On the same day, the central parity of the US dollar against RMB exchange rate also rose from 6.1162 on the previous day to 6.2298 , ending the $33 \%$ appreciation of RMB against the US dollar in the previous decade. The correlation between the subsequent exchange rate market and the trend of the stock market has also been significantly improved. This shows that the reformed exchange rate system can more realistically reflect the supply and demand relationship in the current foreign exchange market and enhance the two-way floating elasticity of the exchange rate market. Therefore, by comparing the changes in the exchange rate market before and after the two key time points, we can easily find that these two institutional reforms have brought about epoch-making changes in the development of China's exchange rate market.

In order to eliminate the influence of variable non-stationarity on the analysis, this paper separately conducts logarithmic difference processing on the Shanghai Composite Index and the exchange rate sequence to obtain two monthly yield series. The descriptive statistics are shown in the following Table 1.

The statistical characteristics of the Shanghai Composite Index and the exchange rate yield series are similar. Although the Shanghai Composite Index's yield skewness is less than 0 with a left tail, and the exchange rate's skewness is much larger than 0 , indicating that there is a long right drag tail, the kurtosis of both are higher than the kurtosis value of the normal distribution of 3 , and the JB test value is above 26, indicating that they have the characteristics of peaks 
Table 1. Descriptive statistical analysis of the yield series.

\begin{tabular}{ccc}
\hline & SHCI & Exchange Rate \\
\hline mean & 0.007770 & -0.001549 \\
Standard deviation & 0.086993 & 0.006870 \\
maximum & 0.242528 & 0.043520 \\
minimum & -0.282783 & -0.020865 \\
skewness & -0.695057 & 1.910121 \\
kurtosis & 4.581581 & 15.75957 \\
J-B test & 26.97236 & 1079.189
\end{tabular}

and thick tails, and reject the sequence of the yields to follow the normal distribution. When further comparing the differences between the two, we can find that the mean and standard deviation of the Shanghai Composite Index's yield series are significantly larger than the exchange rate yield series, that is, the volatility of the stock market far exceeds the exchange rate market's, which is consistent with the situation described in the Figure 1.

\subsection{Empirical Test}

The empirical results are as shown in Table 2. The stock price and the exchange rate are mutually influential, and there is a positive correlation between them. The main concern of this paper is the impact of the foreign exchange market on the stock market. From this perspective, if the exchange rate rises (the dollar appreciates, RMB depreciates), the stock price will rise, and vice versa. A1\% increase of RMB will bring the stock market down by $0.0614 \%$. The test on hypothesis 2 shows the long-term equilibrium effect is significant, that is, the exchange rate affects the stock market. But this is contrary to the conclusion that the expected appreciation of RMB in the domestic stock market leads to the rise of stock prices, indicating that the openness of China's stock market is not high, and the flow of capital is restricted, and the channel for the foreign capital to invest on A-share market is limited. The appreciation and depreciation of RMB have not led to a significant inflow or outflow of foreign capital into the A-share market.

In addition, the appreciation of RMB will also affect corporate profits through imports and exports, thereby affecting stock prices. The appreciation of RMB has reduced the price competitiveness of Chinese goods abroad, and has caused a rapid decline in exports and a fall in stock prices following a decline in the profitability of listed companies. On the contrary, the depreciation of RMB has increased the competitiveness of domestic goods in foreign countries and increased exports, thereby improving the profitability of enterprises and rising stock prices. The exchange rate affects the profitability of micro-enterprises by affecting the import and export of goods, which is reflected in the stock price. 
Table 2. Empirical results. (a) Conditional mean equations: $y_{t}=\mu+\sum_{i=1}^{q} \Gamma_{i} y_{t-i}+\Psi \sqrt{h_{t}}+\varepsilon_{t}$, where $y_{t}=\left(\begin{array}{c}e \\ s\end{array}\right)$ With $q=4$; (b) Conditional variance-covariance structure; (c) Hypotheses testing; (d) Long-term equilibrium effect.

(a)

\begin{tabular}{|c|c|c|}
\hline & Equation 1: Exchange(e) & Equation 2: Stock(s) \\
\hline \multirow{2}{*}{$\mu$} & -0.0041 & 0.0129 \\
\hline & 0.0009 & 0.5482 \\
\hline \multirow{2}{*}{$e_{t-1}$} & 0.1034 & -0.6761 \\
\hline & 0.0684 & 0.4697 \\
\hline \multirow{2}{*}{$e_{t-2}$} & 0.0393 & 0.8574 \\
\hline & 0.4424 & 0.3361 \\
\hline \multirow{2}{*}{$e_{t-3}$} & 0.3860 & -1.6780 \\
\hline & 0.0000 & 0.0486 \\
\hline \multirow{2}{*}{$e_{t-4}$} & 0.0881 & 2.2739 \\
\hline & 0.0341 & 0.0016 \\
\hline \multirow{2}{*}{$s_{t-1}$} & -0.0006 & 0.1016 \\
\hline & 0.8301 & 0.0954 \\
\hline \multirow{2}{*}{$S_{t-2}$} & 0.0012 & -0.0479 \\
\hline & 0.6353 & 0.4128 \\
\hline \multirow{2}{*}{$s_{t-3}$} & 0.0031 & 0.0337 \\
\hline & 0.2521 & 0.5099 \\
\hline \multirow{2}{*}{$S_{t-4}$} & -0.0082 & 0.2033 \\
\hline & 0.0004 & 0.0000 \\
\hline \multirow{2}{*}{$\sqrt{h_{e e, t}}$} & 0.1452 & -1.0667 \\
\hline & 0.0239 & 0.2295 \\
\hline \multirow{2}{*}{$\sqrt{h_{s s, t}}$} & 0.0307 & 0.0061 \\
\hline & 0.0829 & 0.9842 \\
\hline
\end{tabular}

(b)

Conditional Variance-Covariance Structure:
$H_{t}=C^{\prime} C+A^{\prime} \varepsilon_{t-1} \varepsilon_{t-1}^{\prime} A+B^{\prime} H_{t-1} B+D^{\prime} \xi_{t-1} \xi_{t-1}^{\prime} D$
with $f=g=1$
$C=\left[\begin{array}{cc}0.0002 & \\ (0.4524) & \\ 0.0157 & 0.0000 \\ (0.6353) & (1.0000)\end{array}\right] \quad A=\left[\begin{array}{cc}1.2936 & 2.2054 \\ (0.0000) & (0.0612) \\ 0.0583 & 0.3745 \\ (0.0000) & (0.0000)\end{array}\right] \quad B=\left[\begin{array}{cc}0.2056 & 1.2802 \\ (0.0004) & (0.0938) \\ 0.0122 & 0.9165 \\ (0.0000) & (0.0000)\end{array}\right]$

(c)

Hypothesis 1: Stock price has no effect on exchange rate changes

$$
\begin{array}{cc}
H_{0}: \gamma_{e s}^{(1)}=\gamma_{e s}^{(2)}=\gamma_{e s}^{(3)}=\gamma_{e s}^{(4)}=0 & 0.0136 \\
H_{0}: \gamma_{e m}^{(1)}=\gamma_{e m}^{(2)}=\gamma_{e m}^{(3)}=\gamma_{e m}^{(4)}=0 & 0.0167 \\
H_{0}: \psi_{e s}=0 & 0.0829 \\
H_{0}: \psi_{e m}=0 & 0.2295 \\
H_{0}: a_{e s}=b_{e s}=0 & 0.1660 \\
H_{0}: a_{s e}=b_{s e}=0 & 0.0000
\end{array}
$$$$
\text { Hypothesis 2: Exchange rate has no effect on stock prices }
$$$$
\text { Hypothesis 3: Stock price uncertainty has no effect on exchange rate }
$$$$
\text { Hypothesis 4: Exchange rate risk has no effect on stock prices }
$$$$
\text { Hypothesis 6: Stock price uncertainty has no effect on exchange rate risk }
$$ 
(d)

\begin{tabular}{ccc}
\hline & Exchange rate increase $\rightarrow$ Stock price increase & Stock price increase $\rightarrow$ Exchange rate increase \\
\hline Impact on mean value & 0.0614 & 0.0030 \\
Impact on variance & -0.0093 & 0.0000 \\
\hline
\end{tabular}

The GARCH-in-Mean model not only focuses on the impact of changes in the foreign exchange market on the domestic stock market, but also using the equation of variance to explain the uncertainty risk transmission of the foreign exchange market. From the perspective of risk transmission, it is assumed that the variance of stock price has an impact on the exchange rate, but its long-term influence coefficient is very small, close to zero, which can be regarded as no effect. The assumption that the uncertainty of exchange rate has no significant effect on stock price is true according to the results from the data and the correct model we use. Based on the two points above, the risks between the stock market and the foreign exchange market are not contagious, and the risks can be effectively isolated. This further indicates that the openness of China's stock market is not high, and the capital access is restricted, and foreign capital investment channels are limited. Therefore, the exchange rate does not affect the stock market through the flow of capital, but the import and export of goods.

\section{Conclusions}

In order to investigate the correlation between the exchange rate market and the stock market since the implementation of the exchange reform, this paper tests the GARCH-in-Mean model of the Shanghai Composite Index and the exchange rate yield series from June 2005 to August 2017. The empirical results show that: First, there is a two-way influence mechanism between China's stock price and exchange rate market, and there is a positive correlation in the long-term. The appreciation of RMB will bring about a decline in the stock market. Second, from the perspective of market volatility, the uncertainty of exchange rate market will not affect the trend of the stock market, that is, the risk transmission between the two markets is not significant.

Therefore, based on the empirical results and analysis of this paper, we propose the following policy recommendations.

From the perspective of commodity markets, China should actively expand domestic demand, thereby reducing the negative impact of the continuous appreciation of RMB on the stock market. The empirical results of this paper show that the appreciation of RMB will have a negative impact on China's stock market, and it also reflects the shortcomings of China's economic growth. With the continuous reform and gradual marketization of RMB exchange rate mechanism, the long-awaited expectation of RMB appreciation has finally been released. The international market competitiveness of China's commodities has also declined due to the impact of exchange rate changes, and the operating profits of China's export enterprises have been affected with a great challenge. In combi- 
nation with the fact that the economies of various countries are still recovering slowly from the financial crisis, and the background that anti-dumping investigation cases frequently occur in the international market, the domestic consumption potential of China is further released, which can effectively improve China's trade structure, and the partial write-off is due to the appreciation of RMB. The impact is coming and is conducive to maintaining the healthy development of our economy.

From the perspective of capital market, China should continue to improve the openness of financial markets. This will not only expand the investment channels for overseas funds, but also facilitate the process of internationalization of RMB. When a country's currency enters the appreciation channel, the expectation that the currency will continue to appreciate in the future will attract the entry of the national capital, which will lead to an increase in the price of the asset denominated in the local currency [7]. Therefore, the appreciation of RMB should also bring some impact to the stock market. However, the empirical results of this paper show that the transmission of this mechanism is not significant, so it also reveals the fact that the openness of China's financial market is still low. China has always implemented strict capital controls. In the early stage of China's capital market development, capital regulation can effectively reduce the impact of foreign capital on fragile new markets. However, with the rapid growth and development of China's economy, financial markets are gradually developing and improving, so now improving the openness of China's financial market can enhance foreign investors' confidence in China's financial system and the value of RMB, and strengthen their willingness to hold RMB assets, thus effectively promoting the process of internationalization of RMB.

Finally, China should continue to improve the monitoring, evaluation and early warning system of financial risks while improving the openness of the financial market [10]. Although the empirical results show that the risk transmission between the exchange rate market and the stock market is not significant, this conclusion is also closely related to the sample interval selected in this paper. During the period of 2005-2015, the long-term expectation of RMB appreciation will bring a continued appreciation of RMB for ten years, which has weakened the correlation between the two markets to a certain extent. Therefore, while promoting the reform of the sustained financial market, the marketization of the exchange rate mechanism, and the opening of the capital market, we should hold on monitoring and early warning of financial risks.

\section{Conflicts of Interest}

The authors declare no conflicts of interest regarding the publication of this paper.

\section{References}

[1] Liu, L., Meng, Y. and Yang, K. (2015) Structural Changes, CNY/USD Exchange Rate and China's Equity Price: Theoretical Analysis and Empirical. Studies of Interna- 
tional Finance, No. 5, 3-14.

[2] Bu, L., Li, Z. and Zhang, X.Y. (2015) Short-Run International Capital Flows, the RMB Exchange Rate and Asset Price: An Approach Based on the Directed Acyclic Graph. Economic Review, No. 1, 140-151.

[3] Zhao, J.W. and Zhang, J.S. (2013) RMB Exchange Rate, Short-Term International Capital Flow and Stock Price-Based on Re-Testing of Data after Exchange Reform. Journal of Financial Research, No. 1, 9-23.

[4] (1980) Exchange Rates and the Current Account. Dombusch Rudiger, Stanley Fischer. The American Economist.

[5] Deng, S. and Yang, C.J. (2007) The Relationship between China's Stock Market and Foreign Exchange Market after the Reform of Exchange Rate System: An Empirical Study of RMB's Nominal Exchange Rate and Shanghai Composite Index. Journal of Financial Research, No. 12, 55-64.

[6] Ba, S.S. and Yan, M. (2009) The Dynamic Relationship between Stock Prices and Exchange Rates-Empirical Evidence from China. Nankai Economic Studies, No. 3, 46-62.

[7] Li, Y.Q. and Huang, L.H. (2010) On the Relationship between Stock Returnsand Exchange Rate in Chinese Stock Markets. Mathematics in Economics, 27, 1-8

[8] He, C.Y., Liu, L., Xu, X.Y. and Wang, Z.H. (2013) Foreign Intervention, Exchange Rate Movements and Stock Price Fluctuations-Theoretical Model and Empirical Study Based on Investor's Heterogeneity. Economic Research Journal, 48, 29-42+97

[9] Zhang, B.Q. and Li, Y. (2002) Whether the Influence of Exchange Rate on China's Stock Market Exists: Proof from the Autoregressive Distribution Lag Model (ARDL-ECM). Journal of Financial Research, No. 7, 26-35.

[10] Zhang, B., Feng, S.X., Li, X.D. and Wang, H.J. (2008) Exchange Rates and Stock Prices Interactions in China: An Empirical Studies after 2005 Exchange Rate Reform. Economic Research Journal, 41, 70-81+135 